\title{
NOVAS ESTRATÉGIAS TERAPÊUTICAS PARA O TRATAMENTO DA DEPRESSÃO: UMA VISÃO DA QUÍMICA MEDICINAL
}

\author{
Luiz Antonio Soares Romeiro
}

Instituto de Química, Universidade Federal do Rio de Janeiro, Cidade Universitária, 21944-970 Rio de Janeiro - RJ

Carlos Alberto Manssour Fraga* e Eliezer J. Barreiro

Faculdade de Farmácia, Universidade Federal do Rio de Janeiro, Cidade Universitária, CP 68006, 21944-970 Rio de Janeiro - RJ

Recebido em 27/5/02; aceito em 13/8/02

\begin{abstract}
NEW THERAPEUTICAL APPROACHS FOR THE TREATMENT OF DEPRESSION: A MEDICINAL CHEMISTRY VIEW. Depression is a widespread humor disturbance promoted mainly by depletion of biogenic neurotransmitter amines involved in the CNS synapses. Effective drug treatments for depression have been available for more than forty years. Despite its remarkable structural diversity, this paper discuss under the medicinal chemistry point of view, all different classes of "monoamine based" antidepressant drugs, emphasizing the rational design, structure-activity relationships (SAR), biotransformation and physicochemical properties related with antidepressant activity and molecular mechanism of action.
\end{abstract}

Keywords: monoamine oxidase inhibitors; monoamine reuptake inhibitors; serotonin receptor antagonists.

\section{INTRODUÇÃO}

Os distúrbios do humor são graves perturbações do estado emocional, que devem ser distinguidos das alterações do afeto, i.e. manifestações externas de um estado emocional interno ${ }^{1}$. Depressão e mania são freqüentemente considerados como pontos extremos da alteração do humor ou afetiva. Classicamente, estes distintos pólos da variação do humor originaram os termos unipolar, para o estado depressivo, no qual pacientes evidenciam acentuada diminuição do estado normal de humor, e distúrbio bipolar, em que os pacientes alternam, em diferentes momentos, quadros de diminuição (depressão) e exacerbação (mania) de humor. Na prática, a depressão e a mania podem ocorrer simultaneamente, caracterizando um estado afetivo misto ${ }^{2}$.

A depressão consiste em um sentimento que é universalmente experimentado por todos os seres humanos no decorrer de suas vidas. A distinção entre o sentimento depressivo normal e o quadro patológico, que necessita de tratamento médico, é extremamente problemática para pessoas não especializadas em saúde mental. Neste contexto, estigmas e desinformação levaram à crença de que a depressão não seria doença, mas consistiria numa deficiência de caráter, a qual poderia ser superada com esforço pelo indivíduo. Os critérios de diagnóstico dos distúrbios de humor estão em constante evolução, com atualizações nosológicas agrupadas no Manual de Diagnóstico e Estatística dos Distúrbios Mentais (DMS-IV) ${ }^{3}$.

A qualidade do humor, seu grau de desvio da normalidade e sua duração são características chave de um distúrbio afetivo. Contudo, em adição, os clínicos devem avaliar outros sintomas, na formulação de um diagnóstico mais preciso, como as características vegetativas, e.g. sono, apetite, peso e libido; cognitivas, e.g. atenção, tolerância à frustração, memória; comportamentais, e.g. motivação, prazer, interesse, fadiga; físicas ou somáticas, e.g. cefaléia, dores estomacais e tensão muscular e controle do impulso, e.g. suicídio e homicídio.

*e-mail: cmfraga@pharma.ufrj.br

http:Ilwww.farmacia.ufrj.brllassbio
Dados da Organização Mundial de Saúde (OMS) indicam que $13-20 \%$ da população mundial apresentam sintomas depressivos, sendo 2-3\% desse total atribuídos a indivíduos com transtornos afetivos graves, dos quais $15-30 \%$ cometem suicídio ou são potenciais suicidas. Mesmo sob tratamento médico, $30 \%$ dos pacientes com diagnóstico depressivo não respondem à terapia farmacológica, devido ao tempo de latência associado ao surgimento do efeito terapêutico e, ainda, aos seus efeitos adversos, os quais contribuem para o abandono da terapia ${ }^{4}$.

A análise demográfica da depressão revela que as mulheres são mais suscetíveis que os homens numa relação de 2:15, com média etária aos 20 anos e picos aos 40 e após 65 anos. Quanto ao estado civil, pessoas separadas ou divorciadas apresentam os maiores riscos. Inversão de risco é observada entre casados e solteiros: homens casados têm menor disposição à depressão que os solteiros, com o oposto ocorrendo entre as mulheres casadas que apresentam maior risco em relação às solteiras ${ }^{2}$.

Para o acompanhamento do quadro clínico de pacientes após tratamento com antidepressivos foram elaborados 5 termos chave. Três deles estão associados à melhora do paciente e.g. resposta, remissão e recuperação; e os outros dois descrevem quadro clínico desfavorável dos indivíduos e.g. recaída e recorrência. A resposta geralmente significa que o paciente depressivo tem evidenciado redução de, no mínimo, $50 \%$ nos sintomas, avaliado pela Escala de Avaliação dos Sintomas da Depressão de Hamilton ${ }^{2}$. A remissão é termo utilizado quando essencialmente todos os sintomas depressivos desaparecem por período contínuo de 4 a 9 meses. Isto é, o paciente não está no seu melhor, mas atualmente está bem. Após 12 meses, a remissão é então considerada recuperação. A recaída refere-se à piora do quadro clínico antes que ocorra a remissão completa dos sintomas depressivos ou antes que a remissão tenha sido considerada recuperação. Por fim, a recorrência acontece quando o paciente apresenta um quadro de depressão poucos meses após sua recuperação.

Enquanto estimativas sobre a prevalência da depressão variam continuamente ${ }^{6}$, seu impacto tem sido subestimado pelas estatísticas tradicionais, uma vez que estas não abordam a incapacidade dos portadores deste distúrbio de forma adequada. Projeções do impacto da depressão para o ano 2020 colocam-na em segundo lugar no 
"ranking" das doenças incapacitantes, superada apenas pelas doenças cardíacas. Neste contexto, a descoberta de novos fármacos, eficazes, isentos de efeitos colaterais e com reduzida toxicidade, i.e. com menor risco em situações de "overdose", representa significativo investimento em saúde pública, correspondendo, no início desse milênio, a mercado da ordem de 10-20 bilhões de dólares?

\section{Classificação dos distúrbios do humor}

Os distúrbios do humor geralmente são classificados com base em suposições sobre suas origens, distinguindo os diferentes tipos de depressão em três grupos: depressão reativa ou secundária (exógena), depressão maior ou endógena e depressão associada com a doença bipolar (maníaco-depressiva) ${ }^{8}$. As principais características dos tipos de depressão estão descritas resumidamente na Tabela 1.

\section{Patogênese da depressão maior: a hipótese monoaminérgica}

Apesar das origens precisas dos distúrbios de humor permanecerem indefinidas, várias observações indicam que elas podem ser atribuídas, primariamente, a alterações nos padrões de deflagração de certos grupos de neurônios que contêm aminas biogênicas no sistema nervoso central (SNC).

O uso crônico da reserpina (1), no tratamento da hipertensão e esquizofrenia, está caracterizadamente associado ao aumento do risco de aparecimento da depressão em $c a$. 25\% dos indivíduos. Esta evidência clínica, associada à elucidação do principal mecanismo de ação de $\mathbf{1}$, que consiste na inibição do armazenamento de serotonina (5-HT) e norepinefrina (NE) nas vesículas das terminações nervosas, suportou a hipótese de que o efeito depressivo resultava da depleção de uma ou mais aminas biogênicas no cérebro.

Em seguida, demonstrou-se que isoniazida (2), utilizada no tratamento da tuberculose, aliviava a depressão em pacientes com tuberculose crônica e que esses efeitos resultavam de sua capacidade em prevenir a degradação das aminas biogênicas, inibindo a enzima monoamino-oxidase (MAO). Estas observações conduziram ao silogismo, que constituiu a base da hipótese monoaminérgica da depressão $o^{9,10}$, em que o aumento das concentrações das aminas biogênicas cerebrais aliviaria os sintomas depressivos ${ }^{1}$.

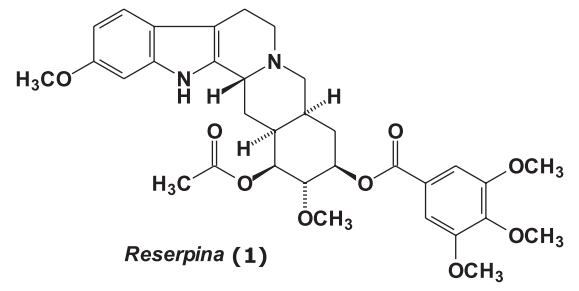<smiles>NNC(=O)c1ccncc1</smiles>

Figura 1. Estruturas da reserpina (1) e da isoniazida (2)

\section{Terapia farmacológica da depressão}

Entre as estratégias terapêuticas utilizadas no alívio da depressão encontram-se a terapia eletroconvulsiva (TEC), os inibidores da monoamino-oxidase (IMAO), os inibidores da recaptação de aminas biogênicas como antidepressivos tricíclicos (ATC), os inibidores seletivos da recaptação de 5-HT (ISRS), NE (ISRN), os inibidores duais de 5-HT e NE (IRSN) e atípicos que agem como antagonistas de 5-HT e os inibidores de sua recaptação (AIRS).

\section{Terapia eletroconvulsiva (TEC)}

Antes da disponibilidade de fármacos antidepressivos, pacientes psiquiatricamente deprimidos eram tratados somente pela TEC, a qual surgiu em 1938. A técnica consiste na aplicação de uma corrente elétrica durante $0,1-1 \mathrm{seg}$, levando o paciente a um estado convulsivo com duração de $1 \mathrm{~min}$, em intervalos de 10-15 min em um total de 520 exposições. O mecanismo de ação associado a esta terapia envolve a liberação de NE e 5-HT, agindo como analgésico e relaxante muscular de curta ação. Este procedimento terapêutico é considerado como rápido e eficaz, principalmente para pacientes com depressão aguda (reincidência de 85\%) e cardiopatas agitados ou psicóticos.

Tabela 1. Diferenciação dos tipos de depressão

\begin{tabular}{|c|c|c|}
\hline Tipo & Características Diagnósticas & Comentários \\
\hline Reativa ou secundária (exógena) & $\begin{array}{l}\text { Perda (eventos vitais adversos) } \\
\text { Doença física (infarto do miocárdio, câncer) } \\
\text { Drogas e fármacos (álcool, anti-hipertensivos, } \\
\text { hormônios) } \\
\text { Outros distúrbios psiquiátricos (senilidade) }\end{array}$ & $\begin{array}{l}\text { Mais de } 60 \% \text { de todas as depressões; } \\
\text { Síndrome depressiva nuclear: depressão, } \\
\text { ansiedade, queixas somáticas, tensão e culpa; } \\
\text { Pode responder espontaneamente ou a } \\
\text { diversos procedimentos terapêuticos. }\end{array}$ \\
\hline Depressão Maior (endógena) & $\begin{array}{l}\text { Anedonia; } \\
\text { Autônoma (não responde a mudanças na vida) } \\
\text { Independência de faixa etária } \\
\text { Distúrbio bioquímico de origem genética } \\
\text { (histórico familiar) }\end{array}$ & $\begin{array}{l}\text { Cerca de } 25 \% \text { de todas as depressões; } \\
\text { Síndrome depressiva nuclear mais sinais } \\
\text { vitais: ritmos anormais de sono, atividade } \\
\text { motora, libido e apetite; } \\
\text { Geralmente responde especificamente a } \\
\text { antidepressivos ou eletroconvulsoterapia; } \\
\text { Tende a recidivar durante toda a vida. }\end{array}$ \\
\hline $\begin{array}{l}\text { Afetiva-bipolar } \\
\text { (maníaco-depressiva) }\end{array}$ & $\begin{array}{l}\text { Caracterizada por episódios de mania (cíclica) } \\
\text { Mania isolada (rara) } \\
\text { Depressão isolada (ocasional) } \\
\text { Mania-depressão (habitual) }\end{array}$ & $\begin{array}{l}\text { Cerca de } 10-15 \% \text { de todas as depressões; } \\
\text { Pode ser erroneamente diagnosticada como } \\
\text { endógena se os episódios hipomaníacos } \\
\text { passarem despercebidos; } \\
\text { Carbonato de lítio estabiliza o humor; } \\
\text { A mania pode incluir o uso de antipsicóticos; } \\
\text { Depressão tratada com antidepressivos. }\end{array}$ \\
\hline
\end{tabular}




\section{Inibidores da enzima monoamino-oxidase (IMAO)}

Os inibidores de MAO (IMAO) estão entre os primeiros fármacos utilizados no tratamento da depressão. A maioria destes agentes inibe não somente a MAO, mas também outras enzimas e interfere com o metabolismo hepático de muitos fármacos ${ }^{11}$.

A MAO é uma enzima portadora de flavina, localizada primariamente na membrana externa das mitocôndrias e encontrada nos terminais nervosos, no fígado e em outros órgãos. Esta enzima oxidativa inativa as aminas biogênicas, tais como NE, DA, 5-HT, triptamina e tiramina, convertendo-as aos aldeídos correspondentes (Esquema 1).

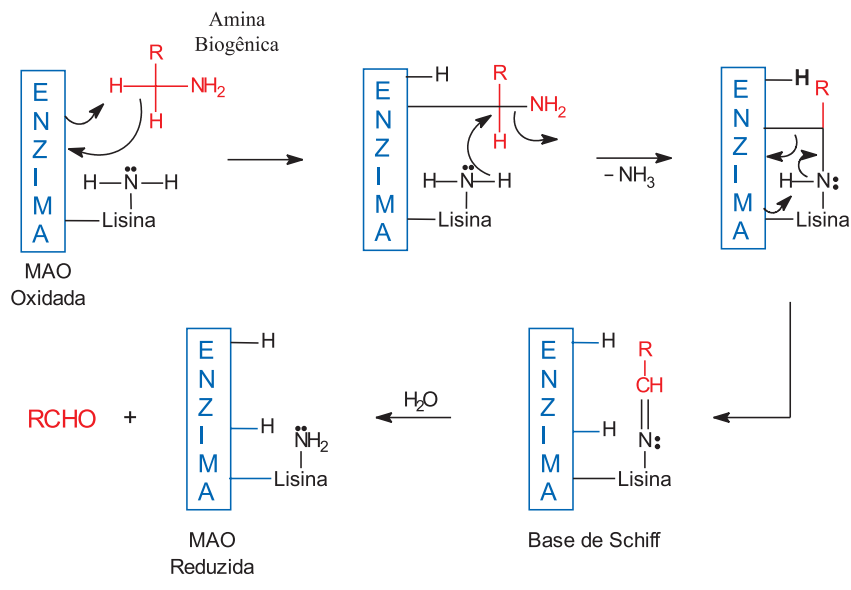

Esquema 1. Representação esquemática do mecanismo de metabolização de aminas biogênicas pela MAO (adaptado da ref. 20)

A MAO existe em duas isoformas: MAO-A e MAO-B, ambas encontradas no tecido neuronal, em proporções distintas e em diferentes regiões do cérebro, tendo a MAO-A preferência por 5-HT e NE, como substratos. Por sua vez, a MAO-B encontra-se preferencialmente nas plaquetas humanas e apresenta maior afinidade por aminas mais hidrofóbicas, como fenetilamina e benzilamina. No cérebro humano, a DA é o substrato predominante da MAO-B ${ }^{12}$, localizada nas células gliais ${ }^{13}$.

Os primeiros inibidores da MAO a serem utilizados no tratamento da depressão foram a fenelzina (3), análogo hidrazínico da fenetilamina, e a tranilcipromina (4), obtida pela ciclização da cadeia lateral de $\mathbf{3}$. Vários destes agentes apresentavam relação estrutural com as anfetaminas e foram sintetizados na tentativa de aumentar suas propriedades estimuladoras centrais. Estes inibidores ligam-se de forma irreversível e não-seletiva às isoenzimas MAO-A e MAO-B.

Com base na diferença de especificidade por substrato e localização celular das isoformas da MAO, inibidores seletivos foram desenvolvidos visando diferentes perfis terapêuticos. Neste contexto, insere-se a segunda geração de inibidores de MAO, representados pela clorgilina (5), inibidor seletivo para a isoforma A (IMAO A), e selegilina (6), inibidor seletivo para a isoenzima B (IMAO B), os quais, embora seletivos, ligam-se irreversivelmente às enzimas ${ }^{14}$. Em seguida, novos inibidores de curta duração de ação, como a meclobemida (7) e RO-19-6327 (8), compuseram a terceira geração de inibidores, reversíveis e seletivos (IRMA e IRMB) ${ }^{15}$. Uma vez que a MAO-B, no cérebro, tem preferência por DA como substrato, seus inibidores seletivos têm sido úteis na terapia da deficiência dopaminérgica associada à doença de Parkinson (Figura 2) ${ }^{16}$.

\section{Antidepressivos tricíclicos - ATC}

Os agentes antidepressivos tricíclicos convencionais (ATCs) fo-

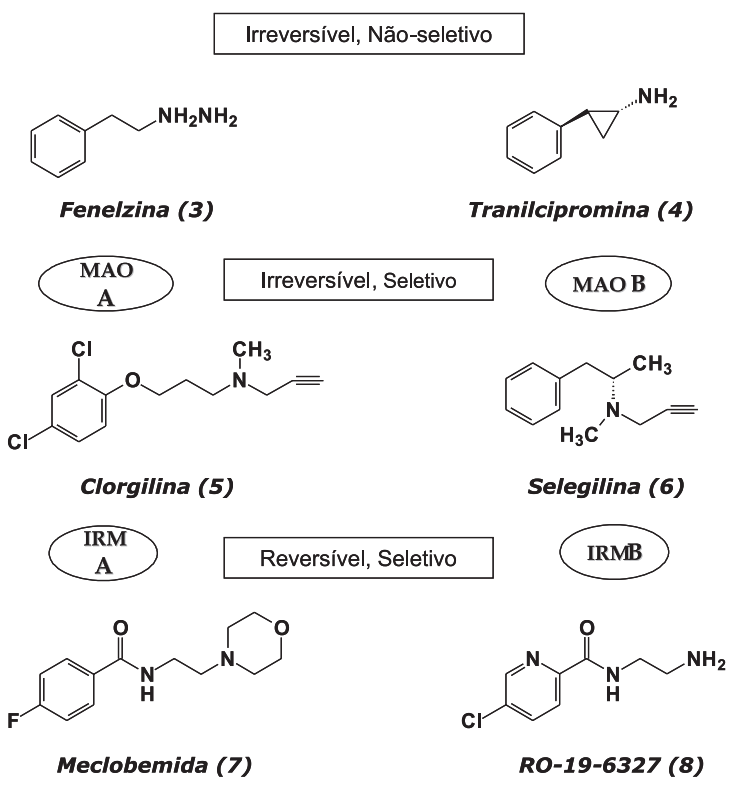

Figura 2. Fármacos inibidores da monoamino oxidase (MAO)

ram descobertos a partir da síntese de derivados dibenzazepínicos, em 1951, inicialmente desenvolvidos e empregados terapeuticamente, por suas propriedades sedativas e analgésicas em animais ${ }^{11}$. Durante a investigação clínica de isósteros fenotiazínicos, Kunh ${ }^{17}$ observou, fortuitamente, que diferentemente dos protótipos, os novos derivados tinham efeito apreciável em pacientes deprimidos (Figura 3) ) $^{18,19}$.

Os ATCs, representados pela imipramina (9) e amitriptilina (10), são relativamente não-seletivos em suas ações, sendo predominantemente caracterizados como inibidores da recaptação de NE e 5-HT. Em geral, os metabólitos monometilados correspondentes e.g. desipramina (11) e nortriptilina (12) são mais potentes e mostram ação mais rápida que $\mathbf{9}$ e $\mathbf{1 0}^{20}$.

Existem indícios de que a habilidade dos fármacos tricíclicos atuarem como inibidores do mecanismo de recaptação neuronal está associada às suas similaridades conformacionais com a NE ${ }^{20}$ (Figura 3 ).

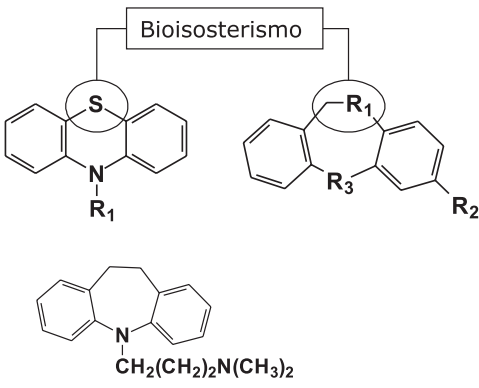

Imipramina (9)

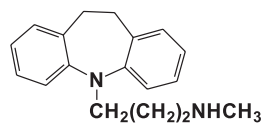

Desipramina (11)
Dibenzazepínicos $\mathrm{R}_{1}=\mathrm{CH}_{2} ; \mathrm{R}_{2}=\mathrm{H} ; \mathrm{R}_{3}=\mathrm{C}, \mathrm{N}$
Recaptação de NE e 5-HT

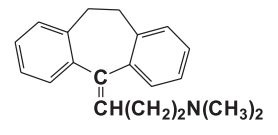

Amitriptilina (10)

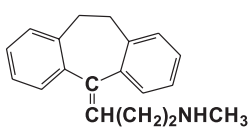

Nortriptilina (12)

Figura 3. Agentes antidepressivos tricíclicos (ATCs)

\section{Derivados heterocíclicos de segunda geração}

A partir de 1980, foram introduzidos novos antidepressivos de 
segunda geração, como a amoxapina (13) e maprotilina (14), estruturalmente relacionados aos tricíclicos clássicos, além da trazodona (15) e nefazodona (16) que, por apresentarem neurofarmacologia menos definida, são considerados atípicos.

Os novos tricíclicos e seus análogos possuem maior seletividade, tendo efeito primário sobre a recaptação de NE, 5-HT, ou DA ${ }^{20}$. Entretanto, não diferem notavelmente dos agentes clássicos em termos de potência. As ações primárias da triazolilpiperazina 15, antidepressivo-sedativo atípico, e de seu congênere 16, são menos bem estabelecidas $^{21}$. Após biotransformados, estes compostos produzem o mesmo metabólito ativo, $m$-clorofenilpiperazina (17) ( $m$ CFP). As ações in vivo da $m \mathrm{CFP}$ envolvem primariamente a ativação dos receptores 5- $\mathrm{HT}_{1 \mathrm{~B}}$ e/ou 5-HT $\mathrm{H}_{2 \mathrm{~A} / 2 \mathrm{C}}$, embora estudos de "binding" com radioligantes não tenham demonstrado seletividade para subtipos do receptor 5-HT ${ }^{22}$. Curiosamente, o metabólito 17, estruturalmente mais simples que 16, altera diversos parâmetros neuroendócrinos e promove profundos efeitos comportamentais, sendo a ansiedade o sintoma mais proeminente ${ }^{23}$.

A elevação da secreção de cortisol e de prolactina, provavelmente, envolve a combinação de ativação dos receptores 5- $\mathrm{HT}_{1}$ e 5-HT ${ }_{2 \mathrm{~A} / 2 \mathrm{C}}$. Adicionalmente, estes receptores parecem mediar parte dos efeitos ansiogênicos da $m$ CFP (17), visto que seus antagonistas reduzem a ansiedade induzida ${ }^{22}$. Vale ressaltar que as atividades da trazodona (15) e $m$ CFP (17) como agonistas dos receptores serotoninérgicos do subtipo 5-HT 1 podem, indiretamente, facilitar a transmissão noradrenérgica ${ }^{22}$.

De uma forma geral, 15 e 16 são antagonistas fracos da recaptação de 5-HT, sendo o efeito da trazodona (15) ca 35 e 700 vezes inferior a aquele dos inibidores seletivos de recaptação de 5-HT, e.g. fluoxetina (18) e paroxetina (19) ${ }^{24}$. Recentemente, $\mathrm{Stahl}^{2}$ classificou separadamente estes agentes, 15 e 16, como antagonistas 5-HT 2A $_{\text {e inibidores }}$ da recaptação de 5-HT (AIRS). A principal distinção entre os AIRS e as outras classes de antidepressivos consiste no seu predominante perfil antagonista $5-\mathrm{HT}_{2 \mathrm{~A}}$ associado à fraca, mas importante, atuação como inibidores da recaptação de 5-HT (Figura 4).
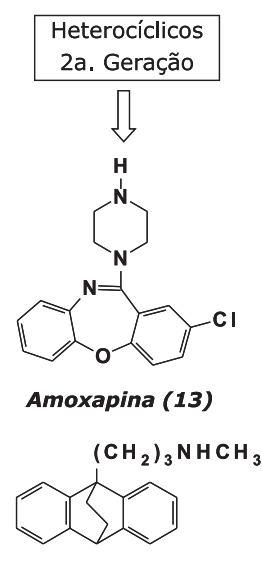

Maprotilina (14)

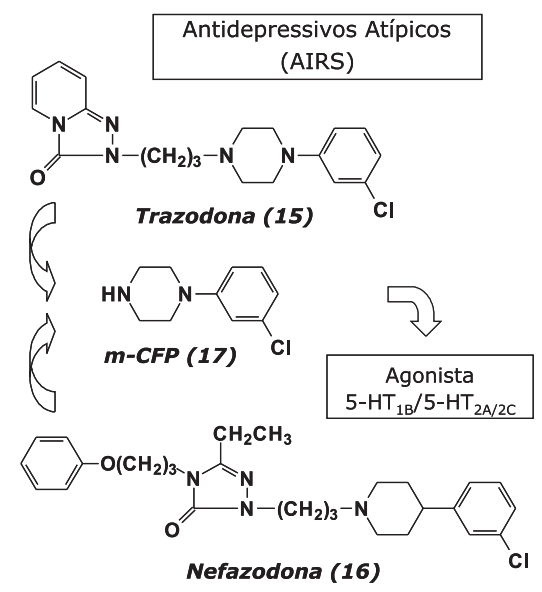

Figura 4. Antidepressivos heterocíclicos e atípicos (AIRS)

\section{Inibidores seletivos da recaptação de serotonina (ISRS)}

Uma das maiores desvantagens de muitos agentes antidepressivos tem sido a multiplicidade de ações farmacológicas, herdada dos fármacos antipsicóticos fenotiazínicos. Neste contexto, as ações antimuscarínicas, anti-histamínicas e bloqueadora dos receptores a adrenérgicos atribuídas aos ATCs contribuem, exclusivamente, para a toxicidade destes fármacos ${ }^{11}$.
O surgimento da fluoxetina (18), a qual se mostrou um antidepressivo altamente seletivo para inibição da recaptação de 5-HT, além de apresentar toxicidade mínima, constituiu uma nova classe de antidepressivos denominados inibidores seletivos da recaptação de serotonina (ISRS) ${ }^{25}$.

Os ISRS estão envolvidos no aumento da neurotransmissão serotoninérgica em algumas áreas do cérebro, por meio do aumento da liberação de 5-HT, como resultado da dessensibilização dos autoreceptores 5-HT somatodendríticos e terminais, os quais, normalmente, exercem efeito negativo sobre os neurônios serotonérgicos ${ }^{26}$.

Fármacos como 18, paroxetina (19), fluvoxamina (20), sertralina (21) e citalopram (22) têm revolucionado a psiquiatria não somente em função de sua eficácia no tratamento da depressão, com reduzidos efeitos adversos, mas também devido à sua capacidade de aliviar outras desordens associadas a disfunções serotoninérgicas. Estas incluem ansiedade, obesidade, bulimia, agressão, síndromes obsessiva-compulsiva e pré-menstrual, ejaculação precoce e distúrbios do estresse pós-traumático ${ }^{26,27}$. Entretanto, a literatura ainda relata que o retardo no orgasmo e a impotência orgásmica (anorgasmia), descritos em homens e mulheres, constituem queixas comuns de pacientes usuários de fármacos ISRS, assim como de ATCs. Estes efeitos adversos têm sido uma das principais causas para o abandono da terapia com ISRS ${ }^{11}$.

A paroxetina (19) é um inibidor potente e seletivo da recaptação sinaptossômica de 5-HT, que atua mediante interação competitiva com o substrato natural no seu transporte ativo pela membrana neuronal ${ }^{28}$. Estudos comparativos, in vitro, da recaptação de vários neurotransmissores em sinaptossomos do hipotálamo de cérebro de ratos demonstraram que a concentração de $\mathbf{1 9}$ capaz de inibir a recaptação de NE foi 320 vezes maior que a concentração necessária para produzir o mesmo efeito com 5-HT e negligenciável para DA e outras aminas. Estudos de "binding" revelaram que, excetuando-se a baixa afinidade por receptores muscarínicos, 19 não interage diretamente com nenhum sítio de receptores de neurotransmissores centrais, incluindo 5- $\mathrm{HT}^{29}$.

Como esperado para os ISRS, 19 causa diminuição nos estoques de 5-HT em plaquetas, por meio da inibição do mecanismo de transporte de membrana. Dos ISRS conhecidos até o momento, citalopram (22) é o mais seletivo, com uma constante de inibição para a recaptação de 5-HT $\left(K_{i}=2,6 \mathrm{nM}\right)$ cerca de 1500 vezes maior que a recaptação de $\mathrm{NE}^{30}$. Entretanto, 19 é o mais potente inibidor do transporte de 5-HT $\left(K_{i}=1,1 \mathrm{nM}\right)^{29}$ (Figura 5).

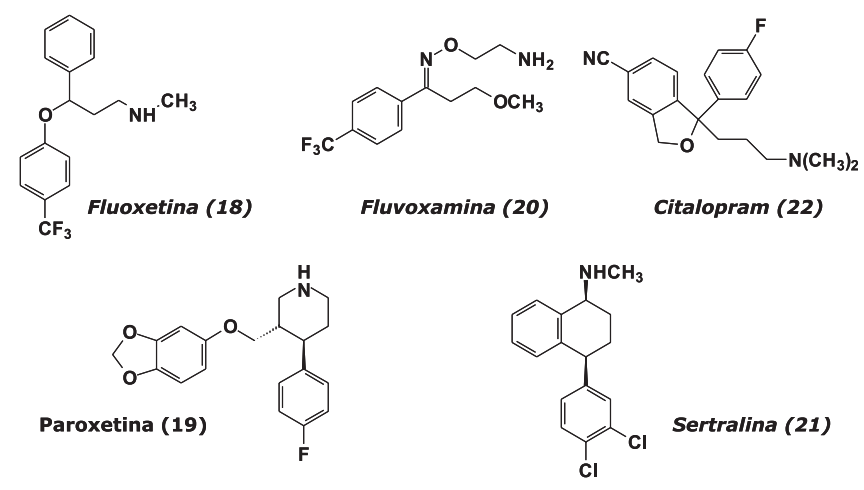

Figura 5. Inibidores seletivos de recaptação da serotonina (ISRS)

\section{O grande enigma: ação farmacológica $\mathrm{x}$ efeitos clínicos}

Os aspectos relativos à diferença entre a ação farmacológica imediata destes agentes e seus efeitos clínicos, alcançados apenas em 2 a 4 semanas, permanecem obscuros. Alguns autores ponderam que o 
aumento da concentração de neurotransmissores na fenda sináptica levaria, inicialmente, a aumento da produção de $\mathrm{AMP}_{c}$, induzindo superatividade dos receptores $\beta$-adrenérgicos, os quais, por meio de "respostas compensatórias lentas", ocasionariam decréscimo na população dos receptores pós-sinápticos (regulação decrescente ou dessensibilização) $)^{31-34}$.

Outros, porém, compreendem que o tempo de latência não pode ser atribuído à regulação decrescente do sistema gerador de AMP acoplado ao adreno-receptor $\beta$, uma vez que a maioria dos ISRS não induz tais efeitos após tratamento crônico ${ }^{28,35-37}$. Mais comumente, acredita-se que o intervalo de tempo observado para a ação clínica e a eficácia limitada de alguns antidepressivos pode estar relacionado à inibição da liberação de 5-HT pelas terminações serotoninérgicas, após administração de ISRS e IMAO ${ }^{38,39}$, levando ao efeito negativo que envolve a ativação dos autoreceptores 5 - $\mathrm{HT}_{1 \mathrm{~A}}$ somatodendríticos, os quais são responsáveis pela atenuação da descarga neuronal nos axônios terminais ${ }^{34,40}$.

\section{Alternativas terapêuticas: novas estratégias}

Novas abordagens terapêuticas para o tratamento da depressão têm sido descritas na literatura, envolvendo antagonistas de canais de cálcio e receptores $\mathrm{NMDA}^{7,41,42}$, bem como a contribuição dos receptores opióides $\sigma^{43}$ e o $\mathrm{GABA}_{\mathrm{A}}{ }^{44}$ na busca de melhor compreensão dos fatores associados à depressão. Recentemente, o surgimento da hipótese neurotrófica ${ }^{45-47}$, a qual envolve a diminuição do fator neurotrófico cerebral (BDNF), modulada pela biossíntese de $\mathrm{AMP}_{\mathrm{C}}$, associada à estimulação de receptores 5 -HT, tem provocado redirecionamento nos estudos dos distúrbios de humor ${ }^{4}$.

A despeito do surgimento de novas estratégias e hipóteses nesse campo de estudos, os receptores 5-HT têm sido alvo de intensas pesquisas nas últimas décadas ${ }^{48}$, uma vez que muitos fármacos efetivos no tratamento da depressão e ansiedade agem sobre este neuromodulador, tanto na forma de inibidores da recaptação de 5-HT (ISRS), quanto agonistas ou antagonistas de seus subtipos de receptores i.e. $5-\mathrm{HT}_{1 \mathrm{~A}}, 5-\mathrm{HT}_{1 \mathrm{~B}}, 5-\mathrm{HT}_{2 \mathrm{~A}}$ e 5-HT ${ }_{2 \mathrm{C}}^{49,50}$.

Outras estratégias envolvendo receptores do subtipo $5-\mathrm{HT}_{1 \mathrm{~B} / 1 \mathrm{D}}{ }^{51}$, $5-\mathrm{HT}_{2 \mathrm{~A} / 2 \mathrm{C}}{ }^{49,50,52,53}$ e 5- $\mathrm{HT}_{4}$ têm sido também descritas na literatura ${ }^{54-57}$.

Adicionalmente, o agente ansiolítico buspirona (23), inicialmente desenvolvido como agente psico-sedativo/neuroléptico ${ }^{58-61}$, e seus derivados gempirona (24) e ipsapirona (25) (Figura 7) foram caracterizados como ligantes com alta afinidade pelos receptores $5-\mathrm{HT}_{1 \mathrm{~A}}{ }^{62}$, estimulando a síntese de novos análogos que atuassem ao nível deste receptor. De modo significativo para este subtipo de receptor serotoninérgico, minuciosos estudos de seu seqüenciamento, clonagem e localização nos tecidos neuronais têm sido desenvolvidos nesta última década ${ }^{63-71}$. Seguindo esta tendência, muitos outros ligantes, de diferentes classes químicas, foram sintetizados e avaliados na busca da compreensão das interações farmacofóricas relevantes para o reconhecimento molecular pelo receptor $5-\mathrm{HT}_{1 \mathrm{~A}}$. Entre estes compostos encontram-se derivados de aminotetralinas, e.g. 8-OH-DPAT (26) e (S)-UH-301 (27) ${ }^{72,73}$; indolilalquilaminas, e.g. bufotenina (28), RU $24969(29)^{74}$; ariloxialquilaminas, e.g. propanolol (30), pindolol (31); alquilpiperidinas, e. g. espiperona (32); arilpiperazinas, e.g. NAN190 (33), WAY 100135 (34), WAY 100635 (35), flesinoxam (36) ${ }^{48,63,75-}$ ${ }^{77}$ e 2-(aminometil)-1,4-dioxano, e.g. MDL 72832 (37), ORG13514 (38), MKC242 (39) ${ }^{78-80}$ (Figuras 6 e 7).

\section{Farmacologia dos receptores 5-HT centrais}

Até o presente momento, existem assinaladas sete famílias de receptores serotoninérgicos, 5-HT ${ }_{1-7}$, compreendendo um total de 14 subtipos de receptores de mamíferos, farmacologica e estruturalmente

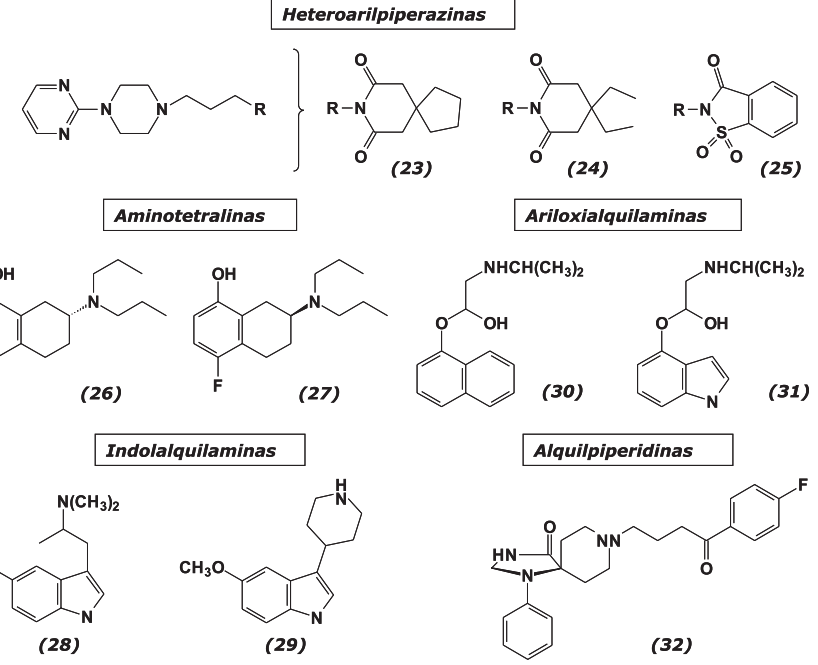

Figura 6. Ligantes de receptores $5-H T_{1 A}$ : heteropiperazinas, indolilalquilaminas, ariloxialquilaminas e alquilpiperidinas

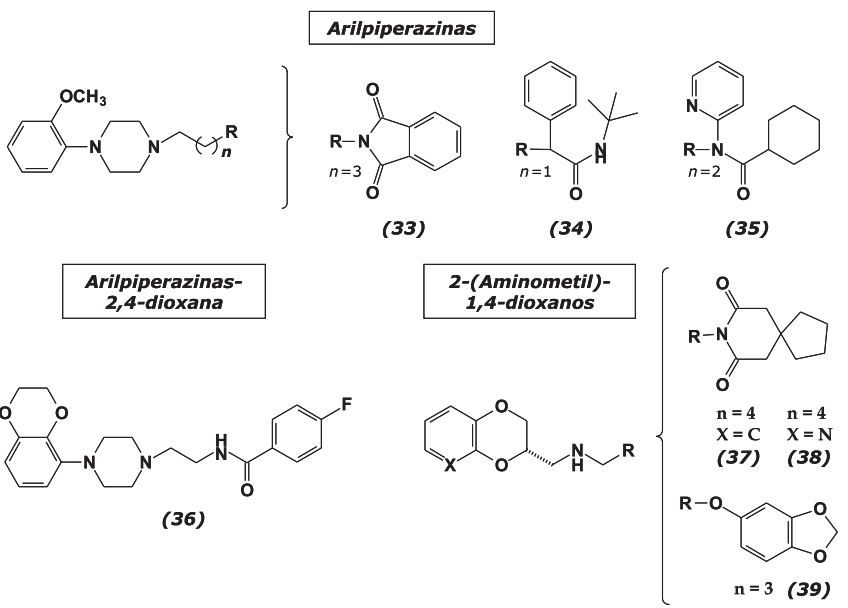

Figura 7. Ligantes de receptores $5-H T_{1 A}$ : arilpiperazinas e 2-(aminometil)1,4-dioxanos

distintos. A família de receptores 5-HT é constituída de $\alpha$-hélices em sete domínios transmembrânicos acoplados à proteína $\mathrm{G}$ como receptores metabotrópicos, sendo $5-\mathrm{HT}_{3}$ o único ionotrópico ${ }^{81}$.

\section{Receptores da família $5-\mathrm{HT}_{1}$}

A caracterização inicial dos receptores da família 5-HT 1 surgiu a partir de estudos com radioligantes, que revelaram alta afinidade para $\left[{ }^{3} \mathrm{H}\right]-5-\mathrm{HT}$ no córtex de ratos, com baixa afinidade por espiperona $(\mathbf{3 2})^{82}$. Estudos posteriores identificaram heterogeneidade dentro do sítio $\left[{ }^{3} \mathrm{H}\right]-5-\mathrm{HT}$, sugerindo inicialmente a existência de receptores do subtipo 5- $\mathrm{HT}_{1 \mathrm{~A}}$ e 5- $\mathrm{HT}_{1 \mathrm{~B}}{ }^{83,84}$, e subseqüentemente receptores 5$\mathrm{HT}_{1 \mathrm{C}}$ (reclassificado como 5- $\mathrm{HT}_{2 \mathrm{C}}{ }^{85}$ ), 5- $\mathrm{HT}_{1 \mathrm{D}}{ }^{86-88}, 5-\mathrm{ht}_{1 \mathrm{E}}{ }^{89}$ e 5-ht ${ }_{1 \mathrm{~F}}{ }^{90-92}$. Os receptores desta família possuem alta homologia em suas seqüências de aminoácidos e todos acoplam negativamente à enzima adenilato ciclase via proteína $\mathrm{G}$ (Tabela 2).

\section{Estrutura do receptor 5-HT}

Os receptores $5-\mathrm{HT}_{1 \mathrm{~A}}$ de humanos e ratos foram identificados por meio de verificação em biblioteca genômica para seqüência 
Tabela 2. Comparação percentual entre homologia de aminoácidos para os diferentes subtipos de receptores 5-HT

\begin{tabular}{|c|c|c|c|c|c|c|c|c|c|c|c|c|c|c|}
\hline & $1 \mathrm{~A}$ & $1 \mathrm{~B}$ & $1 \mathrm{D}$ & $1 \mathrm{E}$ & $1 \mathrm{~F}$ & $2 \mathrm{~A}$ & $2 \mathrm{~B}$ & $2 \mathrm{C}$ & $3 \mathrm{As}$ & 4 & $5 \mathrm{~A}$ & $5 \mathrm{~B}$ & 6 & 7 \\
\hline $1 \mathrm{~A}$ & 100 & & & & & & & & & & & & & \\
\hline 1B & 43 & 100 & & & & & & & & & & & & \\
\hline $1 \mathrm{D}$ & 43 & 63 & 100 & & & & & & & & & & & \\
\hline $1 \mathrm{E}$ & 40 & 48 & 48 & 100 & & & & & & & & & & \\
\hline $1 \mathrm{~F}$ & 42 & 49 & 49 & 57 & 100 & & & & & & & & & \\
\hline $2 \mathrm{~A}$ & 31 & 31 & 29 & 34 & 32 & 100 & & & & & & & & \\
\hline $2 \mathrm{~B}$ & 35 & 27 & 27 & 30 & 29 & 45 & 100 & & & & & & & \\
\hline $2 \mathrm{C}$ & 32 & 28 & 30 & 32 & 33 & 51 & 42 & 100 & & & & & & \\
\hline $3 \mathrm{As}$ & $<10$ & $<10$ & $<10$ & $<10$ & $<10$ & $<10$ & $<10$ & $<10$ & 100 & & & & & \\
\hline 4 & 29 & 32 & 31 & 31 & 34 & 28 & 28 & 28 & $<10$ & 100 & & & & \\
\hline $5 \mathrm{~A}$ & 35 & 35 & 36 & 36 & 37 & 25 & 26 & 28 & $<10$ & 33 & 100 & & & \\
\hline $5 B$ & 38 & 34 & 34 & 34 & 35 & 27 & 29 & 29 & $<10$ & 29 & 69 & 100 & & \\
\hline 6 & 34 & 31 & 32 & 32 & 32 & 28 & 27 & 27 & $<10$ & 27 & 30 & 32 & 100 & \\
\hline 7 & 38 & 37 & 38 & 39 & 38 & 28 & 28 & 28 & $<10$ & 32 & 32 & 34 & 33 & 100 \\
\hline
\end{tabular}

homóloga relativa ao adreno-receptor $\beta_{2}^{93-95}$, constituindo-se o primeiro receptor serotoninérgico a ser completamente seqüenciado. $\mathrm{O}$ receptor $5-\mathrm{HT}_{1 \mathrm{~A}}$ de ratos possui 422 aminoácidos, com homologia de $89 \%$ em relação ao receptor humano, e está introduzido em uma estrutura terciária, típica de uma proteína constituída de $\alpha$-hélices em sete domínios transmembrânicos conectadas por 6 alças, sendo 3 intracelulares e 3 extracelulares, apresentando um resíduo $N$-terminal fora da célula e o resíduo C-terminal no lado citoplasmático ${ }^{96}$ (Figura 8).

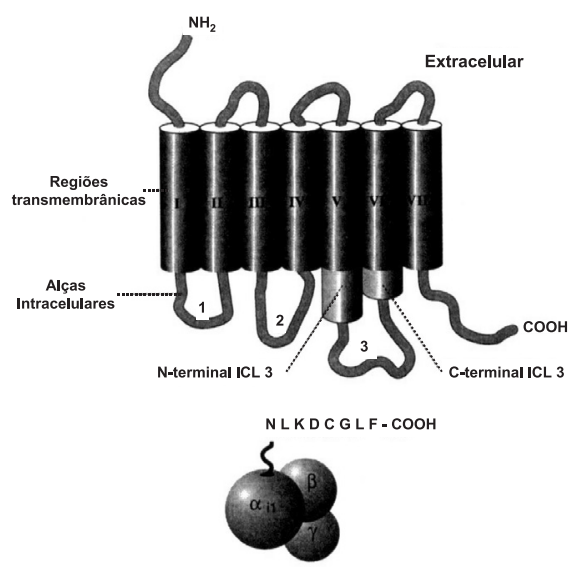

Figura 8. Estrutura do receptor 5-HT ${ }_{I A}$ (adaptado da ref. 31)

\section{Distribuição dos receptores 5-HT}

A distribuição do receptor 5-HT ${ }_{1 \mathrm{~A}}$ no cérebro tem sido extensivamente mapeada por meio de auto-radiografias utilizando gama de radioligantes ${ }^{97-103}$, que revelaram que a densidade de seus sítios ligantes predomina nas áreas límbicas, responsáveis pelos distúrbios psiquiátricos, i.e. hipocampo, septo lateral, áreas corticais (particularmente córtex cingulato e entorinal), e também nos núcleos da rafe mesencefálica (ambos os núcleos dorsal e médio). Em contraste, níveis de sítios ligantes 5 -HT ${ }_{1 \mathrm{~A}}$ nos gânglios basais e cerebelo são raramente detectados.

Há evidências de que os receptores 5-HT 1 estão localizados em ambos os neurônios serotoninérgicos pós-sinápticos (na região frontal) e também sobre os próprios neurônios 5-HT, ao nível da soma e dendritos nos núcleos da rafe mesencefálica e medular ${ }^{104}$. Estudos ao nível celular, utilizando imunocitoquímica e hibridização in situ demonstraram a presença de receptores $5-\mathrm{HT}_{1 \mathrm{~A}}$ em neurônios piramidais corticais e neurônios granulares do hipocampo ${ }^{105}$. Em adi-

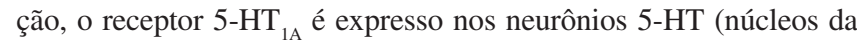
rafe), neurônios colinérgicos (septo) e provavelmente neurônios glutamatérgicos (córtex e hipocampo) ${ }^{105,106}$. Estudos recentes de localização ultra-estutural de receptores $5-\mathrm{HT}_{1 \mathrm{~A}}$ revelaram a evidência de que este subtipo de receptor está presente nas membranas sinápticas, bem como extra-sinapticamente ${ }^{107}$.

\section{Farmacologia de receptores $5-\mathrm{HT}_{1 \mathrm{~A}}$}

As características farmacológicas dos receptores 5 - $\mathrm{HT}_{1 \mathrm{~A}}$ compõem um conjunto a parte de outros membros da família 5- $\mathrm{HT}_{1} \mathrm{e}$ outros receptores $5-\mathrm{HT}^{81}$. Além dos agonistas já abordados anterior-

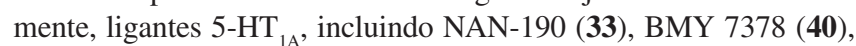
MM-77 (41), MDL 73005 EF (42) e SDZ 216525 (43), foram identificados como antagonistas em vários modelos $5-\mathrm{HT}_{1 \mathrm{~A}}$ pós-sinápticos (Figura 9). Contudo, alguns destes fármacos não se mostraram seletivos, apresentando propriedades agonistas parciais ${ }^{108-114}$, que dificultam sua utilização como sondas investigativas na identificação das características estruturais relevantes para o reconhecimento molecular pelo receptor $5-\mathrm{HT}_{1 \mathrm{~A}}$.
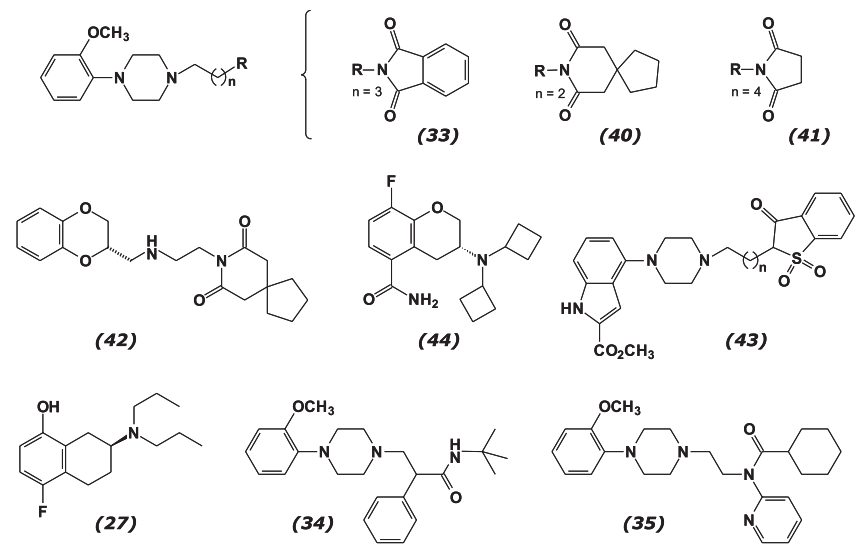

Figura 9. Agonistas parciais e antagonistas de receptores $5-H T_{1 A}$ 
Grande número de antagonistas de receptores 5-HT ${ }_{1 \mathrm{~A}}$ têm sido desenvolvidos, incluindo (S)-UH-301 (27), WAY 100135 (34) (33,114-116 $^{-12}$ e, mais recentemente, NAD-299 (44) $)^{117}$. O derivado piperazínico 35 é o mais potente deste grupo, no qual $\mathbf{4 4}$ aparece como o mais seletivo ${ }^{116,117}$. Dados recentes indicam que $\mathbf{3 4}$ possui propriedades agonistas parciais em alguns modelos farmacológicos ${ }^{113,118}$ (Figura 9).

Agonistas de receptores 5- $\mathrm{HT}_{1 \mathrm{~A}}$ e mesmo a própria 5-HT inibem a atividade neuronal no hipocampo de ratos, córtex frontal e outras áreas do cérebro quando administradas iontoforeticamente in vivo ${ }^{119-123}$. Embora nenhuma diferença singular constitua evidência convincente para a existência de subtipos de receptores 5- $\mathrm{HT}_{1 \mathrm{~A}}$, tal descoberta não seria uma grande surpresa. $\mathrm{O}$ recente desenvolvimento de camundongos transgênicos para receptores $5-\mathrm{HT}_{1 \mathrm{~A}}$ modificados $^{124}$ indicou evidências definitivas para a existência de mais de uma isoforma de receptor $5-\mathrm{HT}_{1 \mathrm{~A}}$.

\section{Relações entre estrutura química de ligantes serotoninérgicos e sua atividade}

Considerando o potencial terapêutico dos ligantes de receptores serotoninérgicos $5-\mathrm{HT}_{1 \mathrm{~A}}$, particularmente aqueles com propriedades antagonistas, as interações de seus grupos farmacofóricos com o biorreceptor, bem como a influência do grupamento espaçador na afinidade, têm sido descritas em detalhes ${ }^{48,67,68,78,96,125-130}$.

\section{Interações farmacofóricas para fenilpiperazinas (FPZ)}

De forma particular para os derivados arilpiperazínicos, foi proposto, como nova abordagem terapêutica para o tratamento da depressão, um modelo geral de atributos estruturais, necessários para seu reconhecimento pelo receptor $5-\mathrm{HT}_{1 \mathrm{~A}}{ }^{78,131}$. Este considera, no mínimo, a presença de um átomo de nitrogênio básico à distância de 5,2-5,8 $\AA$ a partir do centróide do anel aromático, com variação da fenila em uma faixa de 0,9 a 1,5 $\AA$ abaixo e acima do plano do anel piperazínico ${ }^{132}$. Estudos anteriores desenvolvidos por Hibert e colaboradores ${ }^{78,133}$ sugerem que o desvio fora do plano entre o anel aromático e o nitrogênio básico da piperazina poderia variar em torno de 1,6 ̊ para antagonistas e 0,2 A para agonistas (Figura 10). Este modelo foi referendado pelo trabalho de Agarwal e Taylor ${ }^{134}$ que, com base nos resultados de análise comparativa de campo molecular (CoMFA), sugeriram que compostos agonistas tendem a ser mais coplanares que os antagonistas.

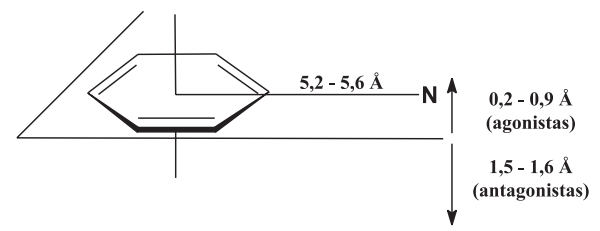

Figura 10. Modelo de reconhecimento molecular de arilpiperazinas pelo receptor $5-H T_{1 \mathrm{~A}}$

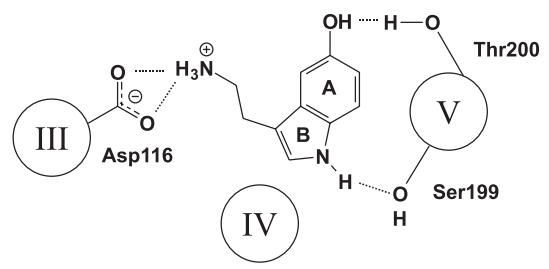

\section{Conformação bioativa de fenilpiperazinas (FPZ)}

Estudos sobre as conformações bioativas de $N$-fenilpiperazinas (FPZ) revelaram que estas adotam, preferencialmente, a conformação cadeira, em que o par de elétrons não-ligante do nitrogênio é quase perpendicular ao plano do anel aromático, podendo participar de seu sistema $\pi^{96,135-137}$. Esta interação, ilustrada na Figura 11, requer uma orientação relativamente coplanar do anel piperazínico em relação ao anel aromático $\mathrm{A}$, de modo que conformações totalmente coplanares (plano angular $\approx 0$ ) apresentam ângulo de torção, $\tau$, definido pelos átomos C6'-C1'-N1-C6, de aproximadamente $30^{\circ}$ ou $-150^{\circ}$.

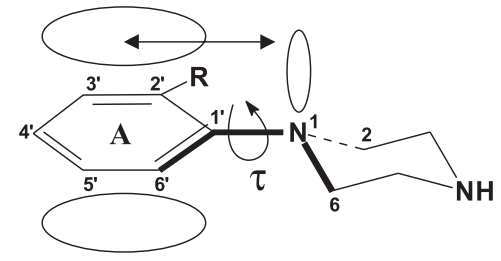

Figura 11. Conformação bioativa de N-fenilpiperazinas (FPZ)

Entretanto, a estabilidade das conformações coplanares de derivados $N$-fenilpiperazínicos dependerá do padrão de substituição do anel fenila, bem como da orientação necessária desses substituintes, quando da possibilidade de interações com resíduos de amino-ácidos do sítio receptor. A presença de substituintes volumosos na posição orto do anel aromático A promove significativa interação estérica com os hidrogênios $\mathrm{C}_{\alpha}$ do anel piperazínico, desviando-os para fora do plano do anel aromático. Esta característica resulta no desacoplamento do sistema de elétrons $\pi$ com o par de elétrons não-ligantes do nitrogênio ${ }^{135}$, promovendo perfil antagonista a $N$-fenilpiperazinas orto-substituídas.

\section{Posicionamento de FPZ no modelo de receptor}

A inserção de FPZ no modelo de receptor 5-HT 1A $_{\mathrm{A}}$ revelou a possibilidade de sua subunidade aromática posicionar-se tanto sobre a subunidade aromática (A) ${ }^{138}$ quanto a pirrólica (B) da $5-\mathrm{HT}^{139}$, por meio de interações com seus elétrons $\pi$ (Figura 12).

Estudos realizados por Kuipers e colaboradores ${ }^{96}$ permitiram evidenciar que as melhores correlações entre estrutura/atividade de FPZ ocorrem quando a orientação do anel benzênico desses compostos coincide com o anel pirrólico da 5-HT, de acordo com a proposição de Glennon e colaboradores ${ }^{96,139}$.

Neste contexto, a afinidade pelo receptor $5-\mathrm{HT}_{1 \mathrm{~A}}$ decresce com a substituição nas posições 3 e 4 do composto 48 (Figura 13), de acordo com os efeitos negativos observados pela substituição nas posições 7 e 1 de 5-HT ${ }^{138,140}$. Da mesma forma, o efeito da introdução de substituintes volumosos na posição 6 dos compostos $\mathbf{4 5}$ e $\mathbf{4 8}$ assemelha-se às modificações correspondentes à posição 2 de 5 -HT e RU24969 (29), mostrando-se desfavoráveis para a afinidade do re-

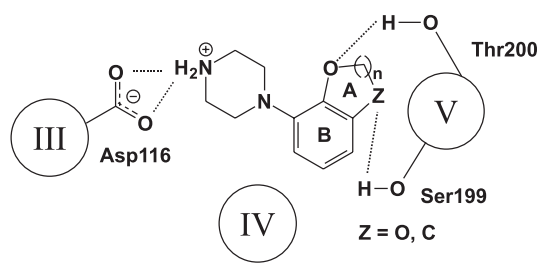

Figura 12. Posicionamento de FPZ no modelo de reconhecimento molecular da 5-HT 
ceptor $^{139,141}$. Por outro lado, a presença dos respectivos substituintes hidroxila e metoxila em 5-HT e 29 são essenciais para a alta afinidade destes compostos ${ }^{96}$ (Figura 13).

\section{Posicionamento no modelo de $\alpha$-hélices transmembrânicas (TM)}

Com relação às possíveis interações no modelo de hélices transmembrânicas, estes compostos estariam localizados entre as hélices TM3, TM4, TM5 e TM6, próximo à parte extracelular do biorreceptor (Figura 14). Desta forma, o nitrogênio básico protonado interage eletrostaticamente com o resíduo Asp116 (TM3), de modo que o complexo formado caracteriza-se por interações com os resíduos de aminoácidos (aa) aromáticos Trp358 e Phe361 (TM4) ${ }^{142,143}$. $\mathrm{O}$ anel fenila do ligante estaria localizado próximo ao resíduo aromático de Trp161 (TM6), de modo que o anel heterocíclico insaturado de 46 levaria à interação do tipo " $\pi$-stacking" anti-paralela com Phe362. A natureza mais polar do sítio de ligação nas proximidades da hélice 5 é causada pela presença dos resíduos Thr160, Ser199 e Thr200, o que está de acordo com as preferências observadas nas interações com os anéis heterocíclicos presentes em 45, 46, e 47. O resíduo Thr200 tem caráter dual, visto que a presença de um grupo metila amplia a região hidrofóbica promovida por Leu366 e Phe362 (TM6), onde os grupos metila de $\mathbf{4 7}$ e $\mathbf{5 0}$ acomodar-se-iam. Adicionalmente, é relevante destacar as interações do substituinte na posição 6 de 5-HT, equivalente à posição 2 de 48, que parecem depender das diferentes contribuições de lipofilicidade.

Seletividade 5-HT $1 \mathrm{~A} \times \alpha_{1}$

$\mathrm{O}$ receptor serotoninérgico $5-\mathrm{HT}_{1 \mathrm{~A}}$, bem como o adreno-receptor $\alpha_{1}$, são membros representativos da superfamília de receptores acoplados à proteína $\mathrm{G}$, os quais, apesar de suas diferenças farmacológicas, mostram algumas características comuns em seus sítios de ligação, devido ao alto grau de similaridade ( $c a .45 \%)$ em suas se-<smiles>NCCc1[se][nH]c2cc(O)cc1-2</smiles>

5-HT<smiles>COc1ccc2[nH]cc(C3=CCNCC3)c2c1</smiles>

(29)

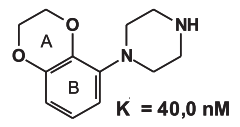

(45)

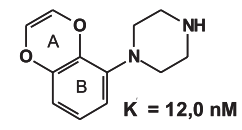

(46)

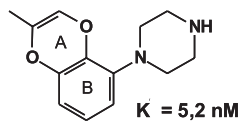

(47)

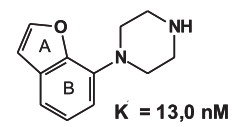

(48)

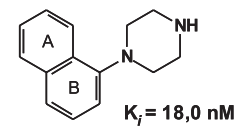

(49)<smiles></smiles>

(48)

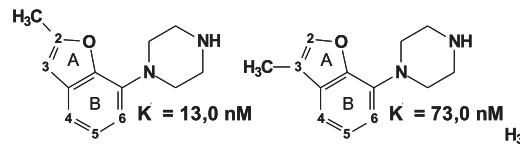

(51)

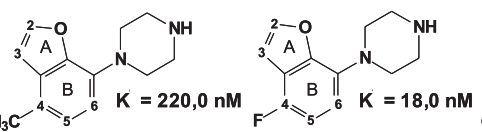

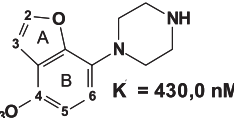

(52)

(53)

(54)

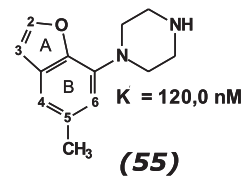<smiles>O=S1(=O)CCN(c2cc(Br)cc3ncoc23)CCO1</smiles>

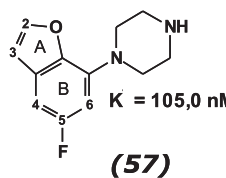
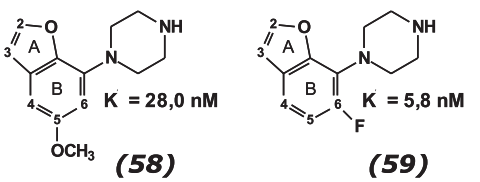

(59)

Figura 13. Posicionamento espacial de N-fenilpiperazinas em relação à 5-HT (Modelo de Glennon)
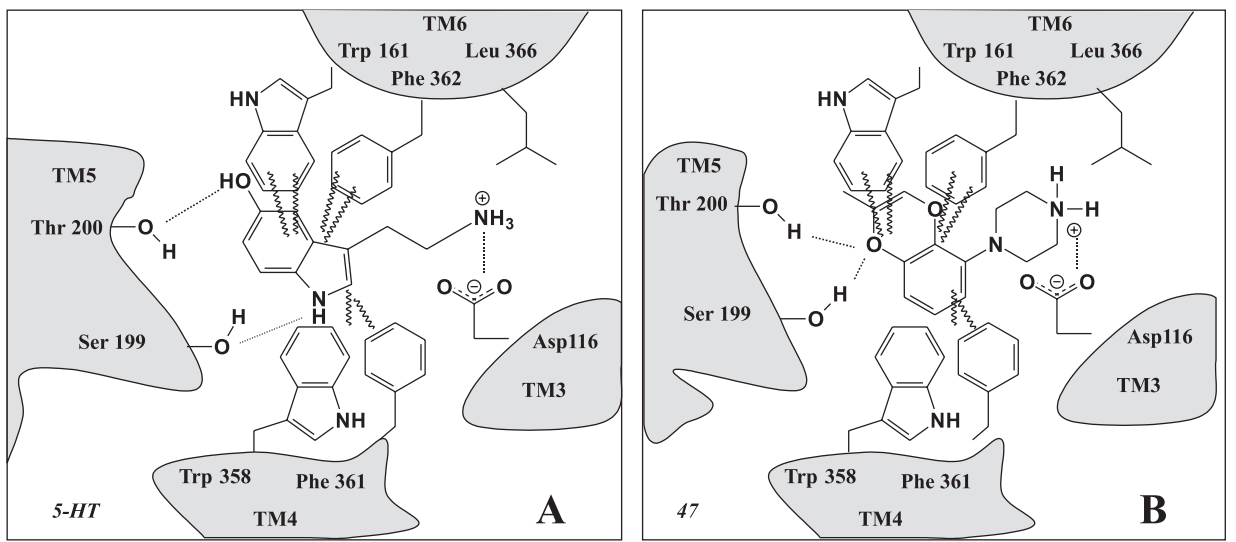

Figura 14. Localização de 5-HT (A) e derivado 47 (B) - TMs do modelo receptor 
qüências de aminoácidos. Como consequiência desta homologia, alguns ligantes sintéticos interagem com ambos receptores, onde, de modo particular, a relação entre a afinidade e seletividade é modulada, em ambos os casos, tanto pelo grupo espaçador quanto pela subunidade não farmacofórica ${ }^{78,131,144,145}$.

\section{Modelo de CoMFA para os receptores 5-HT ${ }_{1 \mathrm{~A}}$ e $\alpha_{1}$}

Estudos desenvolvidos por López-Rodriguez e colaboradores ${ }^{63}$, utilizando a metodologia de CoMFA, permitiram a racionalização das relações entre as estruturas de hidantoilfenilpiperazínicas (Figura 15) e a seletividade 5-HT $\mathrm{H}_{1 \mathrm{~A}}$ e $\alpha_{1}$, explorando funções estéricas e eletrostáticas na modulação da afinidade através de "binding" com os respectivos receptores.

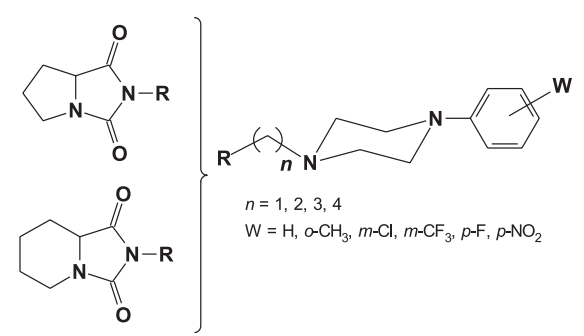

Figura 15. Derivados cicloalquilidantoilfenilpiperazínicos

A comparação entre os mapas de contorno para ambos modelos CoMFA conduziu a aspectos relevantes para a compreensão da seletividade $5-\mathrm{HT}_{1 \mathrm{~A}} / \alpha_{1}$, tais como: a) substituições na posição orto da subunidade fenilpiperazínica de $\mathbf{6 0}$ e $\mathbf{6 1}$ por grupos que apresentem potencial eletrostático negativo são favoráveis para a afinidade em ambos receptores; b) a posição meta da mesma subunidade parece estar envolvida na seletividade $5-\mathrm{HT}_{1 \mathrm{~A}} / \alpha_{1}$, uma vez que o receptor 5 -HT ${ }_{1 \mathrm{~A}}$ pode acomodar substituintes volumosos nesta região do seu sítio ativo (24-70 $\left.\AA^{3}\right)$, enquanto que os requerimentos estéricos para o receptor $\alpha_{1}$ são mais restritos, exibindo um valor otimizado de volume de van der Waals entre 11 e $25 \AA^{3}$; c) para ambos os receptores, a posição para representa uma região onde o volume dos ligantes é limitado, permitindo o acesso e a acomodação de pequenos substituintes, como flúor, na cavidade do biorreceptor e, finalmente d) ambas as características estruturais, subunidade hidantoínica e comprimento da cadeia alquílica, parecem modular não somente a afinidade, mas também a seletividade $5-\mathrm{HT}_{1 \mathrm{~A}}$ e $\alpha_{1}$. Estes resultados estão descritos de forma sucinta na Figura 16.

Em trabalho subseqüente, López-Rodriguez e colaboradores ${ }^{68}$ inferem sobre o volume da subunidade não-farmacofórica, substitu-

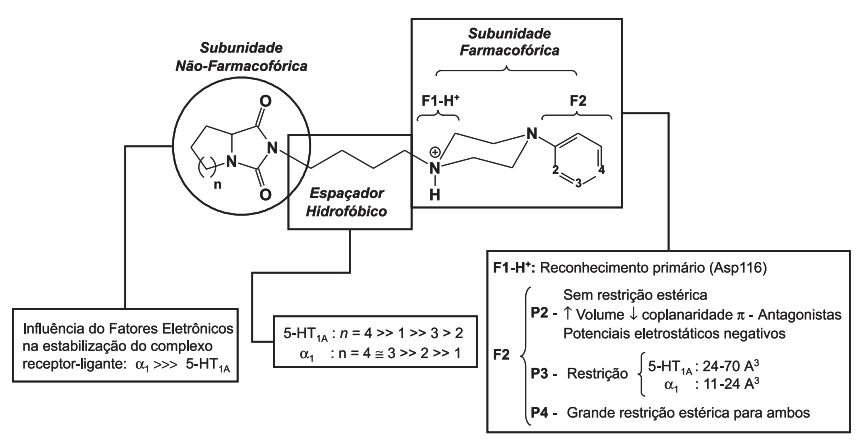

Figura 16. Características estruturais relevantes para a seletividade de ligantes $5-H T_{1 A} / \alpha_{I}$ indo o grupo hidantoína (volume de van der Waals, $\mathrm{V}_{\mathrm{W}} \sim 100 \AA^{3}$ ) por 2,5-pirrolidinodionas, 62 e 63, $\left(\mathrm{V}_{\mathrm{w}} \sim 193-210 \AA^{3}\right)$, mantendo a subunidade fenilpiperazina com variações de espaçador de 1 a 4 unidades metilênicas. Esta modificação, além de elevar os atributos referentes ao componente estérico, em torno de $100 \AA^{3}$, conferiu maior caráter hidrofóbico aos novos ligantes.

Em suas conclusões, os autores ponderam que as conformações estendidas dos derivados protonados, apesar de possuírem maior energia que as respectivas conformações dobradas $\left(\sim 14 \mathrm{KcalMol}^{-1}\right)$, seriam aquelas que melhor descreveriam as variações experimentais de afinidade. As diferenças de energia entre as possíveis conformações poderiam ser compensadas por ganhos entálpicos decorrentes de interações com o biorreceptor (Figura 17).
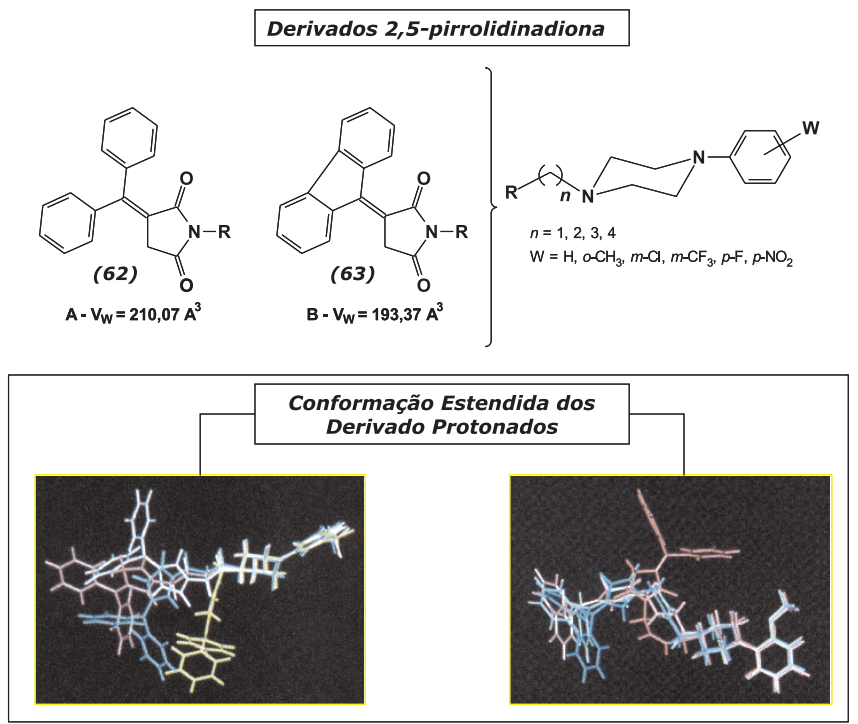

Figura 17. Derivados pirrolidin-2,5-diona e suas conformações estendidas

O mesmo estudo revelou, ainda, que o comprimento otimizado do espaçador, tanto para afinidade $5-\mathrm{HT}_{1 \mathrm{~A}}$ quanto para a interação com o adreno-receptor $\alpha_{1}$, seria de 4 unidades metilênicas, uma vez que compostos que apresentavam $n=3$ mostraram-se inativos para o receptor serotoninérgico e mais seletivos para $\alpha_{1}$. Adicionalmente, a afinidade "anormal" de derivados com $n=1$ pelo receptor $5-\mathrm{HT}_{1 \mathrm{~A}}$ e a não influência da subunidade imídica sobre esta afinidade sugeriram a diferente interação deste tipo de ligante com o receptor, mostrando que uma região não farmacofórica do receptor 5-HT $1 \mathrm{~A}$ teria menos restrição à subunidade 2,5-pirrolidinodiona que a região correspondente do receptor $\alpha_{1}$-adrenérgico. Finalmente, algumas ponderações foram feitas sobre a existência de duas regiões estéricas nãofarmacofóricas no receptor 5-HT ${ }_{1 \mathrm{~A}}$, devido a semelhanças entre os perfis antagonistas de derivados que apresentavam diferentes espaçadores $(n=1$ e $n=4)$.

Alguns autores ${ }^{63}$ sugerem que a otimização da seletividade 5- $\mathrm{HT}_{1 \mathrm{~A}}{ }^{\prime}$ $\alpha_{1}$ estaria contemplada pela síntese de derivados alquilfenilpiperazínicos com substituintes volumosos, apresentando grupos com potenciais eletrostáticos negativos inseridos na posição meta do anel aromático $N$-fenilpiperazínico. Esta hipótese foi confirmada por meio da síntese do derivado (64), contendo o substituinte $m$ isopropilamida, o qual apresentou afinidade para o receptor $5-\mathrm{HT}_{1 \mathrm{~A}}$ $\left(K_{i}=102 \pm 8 \mathrm{nM}\right)$, exibindo ainda alta seletividade frente ao receptor $\alpha_{1}\left(K_{i}>10000 \mathrm{nM}\right)^{77}$. Entretanto, seu bioisóstero sulfona (65), o qual exibiu melhor perfil serotoninérgico $\left(K_{i}=27 \pm 6 \mathrm{nM}\right)$ e seletividade para $\alpha_{1}\left(K_{i}>10000 \mathrm{nM}\right)$, apresentou notável perfil antagônico sobre o receptor dopaminérgico $\mathrm{D}_{2}\left(K_{i}=22,0 \mathrm{nM}\right)$, corroborando a alta 
homologia destes receptores metabotrópicos e suas singularidades quanto ao perfil exigido para a seletividade ${ }^{146}$ (Figura 18).
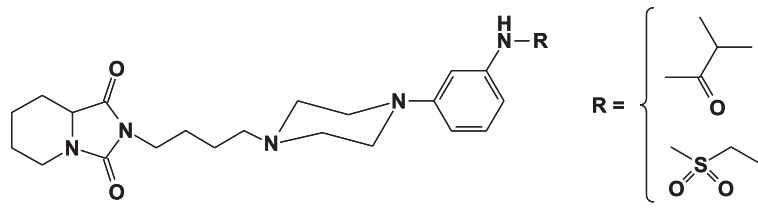

Figura 18. Derivados hidantoilfenilpiperazínico m-substituídos

\section{CONCLUSÕES}

Apesar de toda a evolução alcançada no campo de estudos dos distúrbios psiquiátricos e, de forma especial, no desenvolvimento de estratégias terapêuticas para o alívio da depressão endógena, com o surgimento de fármacos antidepressivos que atuam regulando o aumento e a manutenção das concentrações de aminas biogênicas nos receptores serotoninérgicos e noradrenérgicos, algumas lacunas permanecem obscuras. Estas dizem respeito aos efeitos adversos associados à sua multiplicidade de ações farmacológicas, bem como à elucidação da etiologia e dos neuromoduladores centrais da depressão.

Resumindo as estratégias clássicas implementadas nos últimos 40 anos tem-se que a primeira geração destes agentes, i.e. os antidepressivos tricíclicos (TCAs), bloqueiam as bombas de recaptação de aminas (NE ou 5-HT) permitindo, presumivelmente, maior permanência do neurotransmissor no sítio receptor. No entanto, estes agentes estavam associados a efeitos adversos anticolinérgicos e cardiovasculares. Os inibidores da monoamina oxidase (IMAO) agem no bloqueio do principal caminho degradativo das aminas neurotransmissoras, permitindo seu acúmulo nos estoques pré-sinápticos e, conseqüentemente, possibilitam a sua liberação em concentrações mais elevadas. Contudo, os IMAO relacionavam-se a crises hipertensivas precipitadas por interações com alimentos possuidores de tiramina, que potencialmente libera NE nos terminais nervosos adrenérgicos. A inibição da MAO-A gastro-intestinal promove a rápida absorção da tiramina pela circulação, resultando em grave crise hipertensiva, podendo evoluir para sangramento intracraniano ou lesões em outros órgãos. A segunda geração de antidepressivos, representada pelos inibidores da recaptação de 5-HT (ISRS) e NE (ISRN), antagonistas 5- $\mathrm{HT}_{2 \mathrm{~A}}$ e inibidores da recaptação de serotonina (AIRS), bem como inibidores reversíveis de MAO-A (IRMAs), apresenta derivados com perfil farmacológico mais seletivo e diminutos efeitos colaterais característicos dos fármacos de primeira geração. Infelizmente, este perfil está associado à baixa eficácia terapêutica quando comparados aos ATCs.

A compreensão dos fatores genéticos envolvidos na depressão, a partir de dados obtidos no projeto genoma humano, aliada à evolução das técnicas de clonagem e localização dos receptores serotoninérgicos possibilitarão melhor análise das múltiplas e singulares variáveis, que compreendem as estreitas relações entre a estrutura química e a atividade biológica envolvidas no planejamento racional de novos fármacos antidepressivos. Tais avanços culminarão no desenvolvimento de agentes terapêuticos de última geração isentos de efeitos adversos e que ajam rapidamente nos primeiros dias de tratamento.

\section{AGRADECIMENTOS}

Os autores agradecem ao CNPq, CAPES, FAPERJ e FUJB pelo apoio financeiro e bolsas concedidas. Adicionalmente, os autores agradecem à Universidade Católica de Brasília a concessão da bolsa PIC à L. A. S. Romeiro.

\section{REFERÊNCIAS}

1. Brody, T. M.; Larner, J.; Minneman, K. P.; Neu, H. C.; Farmacologia Humana: da Molecular à Clínica, 2a ed., Guanabara Koogan: Rio de Janeiro, 1997, p. 292.

2. Stahl, S. M.; Essential Psychopharmacology, $2^{\text {nd }}$ ed., Cambridge University Press: Cambridge, 2000.

3. American Psychiatry Association; Diagnostic and Statistical Manual of Mental Disorders (DSM-IV-R), $4^{\text {th }}$ ed., American Psychiatry Association: Washington DC, 1994.

4. Rates, S. M. K.; VII Escola de Verão em Química Farmacêutica e Química Medicinal, Rio de Janeiro, Brasil, 2001.

5. Incluindo-se os sintomas depressivos associados à tensão pré-menstrual e depressão pós-parto.

6. Ohayon, M. M.; Priest, R. G.; Guilleminault, C.; Caulet, M.; Biol. Psychiatry 1999, 45, 300.

7. Skolnick, P.; Eur. J. Pharmacol. 1999, 375, 31

8. American Psychiatry Association; Diagnostic and Statistical Manual of Mental Disorders (DSM-III-R), $3^{\text {th }}$ ed., American Psychiatry Association: Washington DC, 1987.

9. Coppen, A.; Br. J. Psychiatry 1967, 113, 1237.

10. Meltzer, H. Y.; Lowy, M. T.; Psychopharmacology, Raven Press: New York, 1987.

11. Baldessarini, R. J. Em The Pharmacological Basis of Therapeutics; Hardman, J. G.; Limbird, L. E.; Molinoff, P. B.; Ruddon, R. W.; Gilman A. G., eds.; McGraw Hill: New York, 1996, p. 314.

12. Glover, V.; Sandler, M.; Owen, F.; Riley G. J.; Nature 1977, 265, 80.

13. Levitt, P.; Pintar, J. E.; Breakefield, X. O.; Proc. Natl. Acad. Sci. U.S.A. 1982, 79, 6835 .

14. Kuwan, S-W.;Bergeron, J. M.; Abell, C. W.; Psychopharmacology 1992, $106, \mathrm{~S} 1$.

15. Cesura, A. M.; Pletscher, A.; Prog. Drug Res. 1992, 38, 171.

16. Tetrut, J. W.; Langston, J. W.; Science 1989, 245, 519.

17. Kuhn, R.; Am. J. Psychol. 1958, 115, 459.

18. Baldessarini, R. J.; J. Clin. Psychol. 1989, 50, 117

19. Hollister, L. E.; New Engl. J. Med. 1978, 299, 1106.

20. Foye, W. O.; Lemke, T. L.; Williams, D. A.; Principles of Medicinal Chemistry, $4^{\text {th }}$ ed., Lippincott Williams \& Wilkins: Philadelphia, 1995, p. 270.

21. Eison, A. S.; Eison, M. S.; Torrente, J. R.; Wright, R. N.; Yocca, F. D.; Psychopharmacol. Bull. 1990, 26, 311.

22. Sanders-Bush, E.; Mayer, S. E. Ref. 11, p. 183.

23. Murphy, D. L.; Neuropsychopharmacology 1990, 3, 457

24. Bolden-Watson, C.; Richelson E.; Life Sci. 1993, 52, 1023

25. Sommi, R. W.; Crismon, M. L.; Bowden, C. L.; Pharmacotherapy 1987, 7,1

26. Szabo, S. T.; Montigny, C. de; Blier, P.; Br. J. Pharmacol. 1999, 126, 568.

27. Raap, D. K.; Van de Kar, L.; Life Sci. 1999, 65, 1217.

28. Dechant, K. L.; Clissold, S. P.; Drugs 1991, 41, 224.

29. Thomas, D. R.; Nelson, D. R.; Johnson, A. M.; Psychopharmacology 1987, 93, 193.

30. Hyttel, J.; Neuropsychopharmacol. Biol. Psychiatry 1982, 6, 277.

31. Broekkamp, C. L. E.; Leysen, D.; Peeters, B. W. M. M.; Pinder, R. M.; J. Med. Chem. 1995, 38, 4615.

32. Pinder, R. M.; Wieringa, J. H.; Med. Res. Rev. 1993, 13, 259.

33. Norman. T. R.; Leonard, B. E.; CNS Drugs 1994, 2, 120.

34. Leonard, B. E.; CNS Drugs 1995, 4, 1.

35. Peroutka, S. J.; Snyder, S. H.; Science 1980, 210, 88.

36. Hyttel, J.; Overo, K. F.; Arnt, J.; Psychopharmacology 1984, 83, 20.

37. Hrdina P. D.; Vu, T. B.; Synapse 1993, 14, 324.

38. Adell, A.; Artigas, F.; Naunyn-Schmiedeberg's Arch. Pharmacol. 1991, 343, 237.

39. Artigas, F.; Trends Pharmacol. Sci. 1993, 14, 262.

40. Romero, L.; Casanovas, J. M.; Hervás, I.; Cortés, R.; Artigas, F. Em Antidepressants: New Pharmacological Strategies; Skolnick, P., ed.; Humana Press: New Jersey, 1997, cap. 1.

41. Pucilowski, O. Ref. 40, cap. 5.

42. Trullas, R. Ref. 40, cap. 6.

43. Leonard, B. E. Ref. 40, cap. 9

44. Tao, R.; Auerbach, S. B.; J. Psychopharmacol. 2000, 14, 100.

45. Duman, R. S.; Neuropsychopharmacology 1999, $20,97$.

46. Duman, R. S.; Nibuya, M.; Vaidya, V. A. Ref. 40, cap. 10. 
47. Duman, R. S.; Malberg, J.; Nakagawa, S.; D’as, C.; Biol. Psychiatry 2000 $48,732$.

48. Orjales, A.; Alonso-Cires, L.; Labeaga, L.; Corcóstegui, R.; J. Med. Chem. 1995, 38, 1273.

49. Jenck, F.; Moreau, J. L.; Mutel, V.; Martin, J. R.; Prog. Neuropsychopharmacol. Biol. Psychiatry 1994, 18, 563.

50. Hartig, P. R.; Experientia (Suppl.) 1994, 71P, 93.

51. Matzen, L.; Van Amsterdam, C.; Rautenberg, W.; Greiner, H. E.; Harting, J.; Seyfried, C. A.; Böttcher, H.; J. Med. Chem. 2000, 43, 1149.

52. Giannangeli, M.; Cazzolla, N.; Luparini, M. R.; Magnani, M.; Mabilia, M.; Picconi, G.; Tomaselli, M.; Baiocchi, L.; J. Med. Chem. 1999, 42, 336.

53. Bromidge, S. M.; Dabbs, S.; Davies, S.; Duckworth, D. M.; Forbes, I. T.; Jones, G. E.; Jones, J.; King, F. D.; Saunders, D. V.; Blackburn, T. P.; Holland, V.; Kennett, G. A.; Lightowler, S.; Middlemiss, D. N.; Riley, G. J.; Trail, B.; Wood, M. D.; Bioorg. Med. Chem. Lett. 2000, 10, 1863.

54. Diouf, O.; Depreux, P.; Chavatte, P.; Poupaert, H.; Eur. J. Med. Chem. 2000, $35,699$.

55. Takeda, M.; Tsukamoto, K.; Sakurai-Yamashita, Y.; Suzuki, T.; Taniyama, K.; Jpn. J. Pharmacol. 2000, 82, 138.

56. Sanger, G. J.; Yoshida, M.; Yahyah, M.; Kitazumi, K.; Br. J. Pharmacol. 2000, 130, 706 .

57. Robichaud, A. D.; Largent, B. L.; Annu. Rep. Med. Chem. 2000, 35, 11.

58. Wu, Y.-H.; Smith, K. R.; Rayburn, J. W.; Kissel, J. W.; J. Med. Chem. 1969, $12,876$.

59. Wu, Y.-H.; Rayburn, J. W.; Allen, L. E.; Ferguson, H. C.; Kissel, J. W.; J. Med. Chem. 1972, 15, 477.

60. Yevich, J. P.; New, J. P.; Smith, D. W.; Lobeck, W. G.; Catt, J. D.; Minielli, J. L.; Eison, M. S.; Taylor, D. P.; Riblet, L. A.; Temple, D. L. Jr.; J. Med. Chem. 1986, 29, 359 .

61. New, J. S.; Yevich, J. P.; Eison, M. S.; Taylor, D. P.; Eison, A. S.; Riblet, L. A.; VanderMaelen, C. P.; Temple, D. L. Jr.; J. Med. Chem. 1986, 12, 422.

62. Traber, J.; Glaser, T.; Trends Pharmacol. Sci. 1987, 8, 432.

63. López-Rodriguez, M. L.; Morcillo, M. J.; Fernadez, E.; Porras, E.; Murcia, M.; Sanz, A. M.; Orensanz, L.; J. Med. Chem. 1997, 40, 2653.

64. Chilmonczyk, Z.; Cybulski, A.; Szelejewska-Wozniakowska, A.; Les, A.; J. Med. Chem. 1995, 38, 1701.

65. Van Steen, B. J.; van Wijngaarden, I.; Tulp, M. Th. M.; Soudijn, W.; J. Med. Chem. 1995, 38, 4303.

66. Terán, C.; Santana, L.; Uriarte, E.; Fall, Y.; Unelius, L.; Tolf, B.-R.; Bioorg. Med. Chem. Lett. 1998, 8, 3567.

67. López-Rodriguez, M. L.; Rosado, M. L.; Benhamú, B.; Morcillo, M. J.; Sanz, A. M.; Orensanz, L.; Beneytez, M. E.; Fuentes, J. A.; Manzanares, J.; J. Med. Chem. 1996, 39, 4439.

68. López-Rodriguez, M. L.; Morcillo, M.; Rovat, T. K.; Fernández, E.; Vicente, B.; Sanz, A. M.; Hernández, M.; Orensanz, L.; J. Med. Chem. 1999, 42, 36.

69. López-Rodriguez, M. L.; Benhamú, B.; Ayala, D.; Rominguera, J. L.; Murcia, M.; Ramos, J. A.; Viso, A.; Tetrahedron 2000, 56, 3245.

70. Chilmonczyk, Z.; Farmaco 2000, 55, 191.

71. Modica, M.; Santagati, M.; Santagati, A.; Russo, F.; Cagnotto, A.; Goegan, M.; Mennini, T.; Bioorg. Med. Chem. Lett. 2000, 10, 1089.

72. McCall, R. B.; Romero, A. G.; Bienkowski, M. J.; Harris, D. W.; McGuire, J. C.; Piercey, M. F.; Shuck, M. E.; Smith, M. W.; Svensson, K. A.; Schereur, P. J. K. D.; Carlsson, A.; Vonvoigtlander, P. F.; J. Pharmacol. Exp. Ther. 1994, 271, 875.

73. Björk, L.; Cornfield, L. J.; Nelson, D. L.; Hillver, S. -E.; Andén, N. -E.; Lewander, T.; Hacksell, U.; J. Pharmacol. Exp. Ther. 1991, 258, 58.

74. Glennon, R. A.; J. Med. Chem. 1986, 30, 1.

75. Glennon, R. A.; Drug Dev. Res. 1992, 26,251.

76. Hacksell, U.; Liu, Y.; Yu, H.; Vallgarda, J.; Höök, B. B.; Johansson, A. M.; Lewander, T.; Drug Des. Discovery 1993, 9, 287.

77. Kuipers, W.; van Steen, B. J.; Wijngaarden, I.; Tulp, M, T. M.; Soudin, W.; Drug Des. Discovery 1994, 11, 231.

78. Hibert, M. F.; Gittos, M. W.; Middlesmiss, D. N.; Mir, A. K.; Fozard, J. R.; J. Med. Chem. 1988, 31, 1087.

79. Comoy, C.; Benarab, A.; Leinot, M.; Monteil, A.; Guillaumet, G.; Farmaco 1999, 54, 791 .

80. Matsuda, T.; Somboonthum, P.; Suzuki, M.; Asano, S.; Baba, A.; Eur. J. Pharmacol. 1995, 280, 235.

81. Hoyer, D.; Clarke, D. E.; Fozard, J. R.; Mylecharane, E. J.; Martin, G. R.; Humphrey, P.P; Pharmacol. Rev. 1994, 46, 153

82. Peroutka, S. J.; Snyder, S. H.; Mol. Pharmacol. 1979, 16, 687.

83. Pedigo, N.W.; Yamamura, H. I.; Nelson, D. L.; J. Neurochem. 1981, 36, 205.

84. Middlesmiss, D. N.; Fozard, J. R.; Eur. J. Pharmacol. 1983, 90, 151.

85. Pazos, A.; Hoyer, D.; Palacios, J. M.; Eur. J. Pharmacol. 1984, 106, 539.
86. Hoyer, D.; Engel, G.; Kalkman, H. O.; Eur. J. Pharmacol. 1985, $118,1$. 87. Hoyer, D.; Engel, G.; Kalkman, H. O.; Eur. J. Pharmacol. 1985, 118, 13. 88. Heuring, R. E.; Peroutka, S. J.; J. Neurosci. 1987, 7, 894

89. Leonhardt, S.; Herrick-Davis, K.; Teitler, M.; J. Neurochem. 1989, 53, 465.

90. Amlaiky, N.; Ramboz, S.; Boschert, U. U.; Plassat, J. L.; Hen, R.; J. Biol. Chem. 1992, 267, 19761.

91. Adham, N.; Borden, L. A.; Schechter, L. E.; Gustafson, E. L.; Cochran, T. L.; Vaysse, P. J. J.; Weinshank, R. L.; Branchek, T. A.; NaunynSchmiederberg's Arch. Pharmacol. 1993, 348, 566.

92. Adham, N.; Kao, H. T.; Schechter, L. E.; Bard, J.; Olsen, M.; Urquhart, D.; Durkin, M.; Hartig, P. R.; Weinshank, R. L.; Branchek, T. A.; Proc. Natl. Acad. Sci. U.S.A. 1993, 90, 408.

93. Kobilka, B. K.; Frielle, T.; Colllins, S.; Yangfeng, T.; Kobilka, T. S.; Francke, U.; Lefkowitz, R. J.; Caron, M. G.; Nature 1987, 329, 75.

94. Fargin, A.; Raymond, J. R.; Lohse, M. J.; Kobilka, T. S.; Caron, M. G.; Lefkowitz, R. J.; Nature 1988, 335, 358.

95. Albert, P. R.; Zhou, Q. Y.; Van Tol, H. H. M.; Bunzow, J. R.; Civelli, O.; J. Biol. Chem. 1990, 265, 5825.

96. Kuipers, W.; Van Wijngaarden, I.; Kruse, C. G.; Amstel, M. T.-H.-V.; Tulp, M. T. M.; Ijzerman, A. P.; J. Med. Chem. 1995, 38, 1942.

97. Pazos, A.; Palacios, J. M.; Brain Res. 1985, 346, 205.

98. Weissmann-Nanopoulus, D.; Mach, E.; Margre, J.; Neurochem. Int. 1985, 7,1061 .

99. Hoyer, D.; Pazos, A.; Probst, A.; Palacios, J. M.; Brain Res. 1986, 376, 85 .

100. Verge, D.; Daval, G.; Marcinkiewicz, M.; Patey, A.; Elmestikawy, S.; Gozlan, H.; Hamon, M.; J. Neurosci. 1986, 6, 3473.

101. Radja, F.; Laporte, A.-M.; Daval, G.; Verge, D.; Gozlan, H.; Hamon, M.; Neurochem. Int. 1991, 18, 1.

102. Khawaja, X.; Brain Res. 1995, 673, 217.

103. Kung, M. P.; Frederick, D.; Um, M.; J. Pharmacol. Exp. Ther. 1995, 272, 429.

104. Barnes, N. M.; Sharp, T.; Neuropharmacology 1999, 38, 1083.

105. Francis, P. T.; Pangalos, M. N.; Pearson, R. C.; J. Pharmacol. Exp. Ther. 1992, 261, 1273 .

106. Kia, H. K.; Brisorgueil, M.-J.; Daval, G.; Langlois, X.; Hamon, M.; Verge, D.; Neuroscience 1996, 74, 143.

107. Kia, H. K.; Brisorgueil, M.-J.; Hamon, M.; Calas, A.; Verge, D.; J. Neurosci. 1996, 46, 697.

108. Hjorth, S.; Sharp, T.; Life Sci. 1990, 265, 707.

109. Sharp, T.; Backus, L. I.; Hjorth, S.; Branswell, S. R.; Grahame-Smith, D. G.; Eur. J. Pharmacol. 1990, 176, 331.

110. Sharp, T.; McQuade, R.; Fozard, J. R.; Neuropharmacol. 1996, 35, 735.

111. Fletcher, A.; Cliffe, I. A.; Dourish, C. T.; Trends Pharmacol. Sci. 1993, $14,41$.

112. Hoyer, D.; Boddeke, H. W. G. M.; Trends Pharmacol. Sci. 1993, 14, 270.

113. Schoeffter, P.; Bobirnac, I.; Boddeke, E.; Hoyer, D.; Neuropharmacol. 1997, $36,429$.

114. Hillver, S. E.; Björk, L.; Li, Y. L.; Svensson, B.; Ross, R.; Anden, N. E.; Hacksell, U.; J. Med. Chem. 1990, 33, 1541.

115. Fletcher, A.; Bill, D. J.; Cliffe, I. A.; Dover, G. M.; Forster, E. A.; Haskins, J. T.; Jones, D.; Mansell, H. L.; Reilly, Y.; Eur. J. Pharmacol. 1993, 237, 283.

116. Fletcher, A.; Forster, E. A.; Bill, D. J.; Brown, G.; Cliffe, I. A.; Hartley, J. E.; Jones, D. E.; McLenachan, A.; Atanhope, K. J.; Critchley, D. J. P.; Childs, K. J.; Middlefell, V. C.; Lanfumey, L.; Corradetti, R.; Laporte, A. M.; Gozlan, H.; Hamon, M.; Dourish, C. T.; Behav. Brain Res. 1996, 73, 337.

117. Johansson, L.; Sohn, D.; Thorberg, S. O.; Jackson, D. M.; Kelder, D.; Larsson, L. G.; Renyi, L.; Ross, S. B.; Wallsten, C.; Eriksson, H.; Hu, P. S.; Jerning, E.; Mohell, N.; Westlind, D. A.; J. Pharmacol. Exp. Ther. 1997, $283,216$.

118. Davidson, C.; Ho, M.; Price, G. W.; Jones, B. J.; Stamford, J. A.; Br. J. Pharmacol. 1997, 121, 737.

119. Segal, M.; Brain Res. 1975, 94, 115.

120. De Montigny, C.; Blier, P.; Chaput, Y.; Neuropharmacology 1984, 23, 1511.

121. Sprouse, J. S.; Aghajanian, G. K.; Neuropharmacology 1988, 27, 707.

122. Ashby, C. R.; Edwards, E.; Wang, R. Y.; Synapse 1994, 17, 173.

123. Ashby, C. R.; Minabe, Y.; Toor, A.; Fishkin, L. D.; Granoff, M. I.; Wang, R. Y.; Drug Dev. Res. 1994, 31, 228.

124. Parks, C. L.; Robinson, P. S.; Sibille, E.; Shenk, T.; Toth, M.; Proc. Natl. Acad. Sci. U.S.A. 1998, 95, 10734

125. Ho, B. Y.; Karschin, A.; Branchek, T.; Davidson, N.; Lester, H. A.; FEBS Lett. 1992, 312, 259.

126. Sylte, I.; Edvardsen, O.; Dahl, S. G.; Protein Eng. 1993, 6, 691.

127. Mokrosz, J .L.; Pietrasiewicz, M.; Duszynska, B.; Cegla, M. T.; J. Med. Chem. 1992, 35, 2369. 
128. Peglion, J. -L.; Canton, H.; Bervoets, K.; Audinot, V.; Brocco, M.; Gobert, A.; Marouille-Girardon, S. Le.; Millan, M. J.; J. Med. Chem. 1995, 38, 4044.

129. Kuipers, W.; Kruse, C. G.; van Wijngaarden, I.; Standaar, P. J.; Tupl, M. T.; Veldman, N.; Spek, A. L.; Ijzerman, A. P.; J. Med. Chem. 1997, 40, 300.

130. Ishizumi, K.; Kojima, A.; Antoku, F.; Chem. Pharm. Bull. 1991, 39, 2288.

131. El-Bermawy, M. A.; Lotter, H.; Glennon, R. A.; Med. Chem. Res. 1992, 2 , 290.

132. Bolis, G.; Pillan, A.; Mantegani, S.; Brambilla, E.; Dolmella, A.; J. Mol. Modeling 1995, 1, 188.

133. Hibert, M. F.; McDermott, I.; Middlesmiss, D. N.; Mir, A. K.; Fozard, J. R.; Eur. J. Med. Chem. 1989, 24, 31.

134. Agarwal, A.; Taylor, E. W.; J. Comput. Chem. 1993, 14, 237.

135. Gilli, G.; Bartolasi, V.; J. Am. Chem. Soc. 1979, 101, 7704

136. Huff, J. R.; King, S. W.; Saari, W. S.; Springer, J. P.; Martin, G. E.; Williams, M.; J. Med. Chem. 1985, 28, 945.

137. Dijkstra, G. D. H.; Recl. Trav. Chim. Pays-Bas 1993, 112, 151.
138. Hibert, M.; Middlemiss, D. N.; Fozard, J. R. Em Brain 5-HT Receptors; Dourish, C. T.; Ahlenius, S.; Hutson, P. H., eds.; Ellis Horwood LTd: Chichester, 1987, p. 27.

139. Glennon, R. A.; Naiman, N. A.; Pierson, M. E.; Smith, J. D.; Ismaiel, A. M.; Titeler, M.; Lyon, R. A.; J. Med. Chem. 1989, 32, 1921.

140. Hoyer, D. Em The Peripheral Actions of 5-Hydroxytryptamine; Fozard, J. R., ed.; Oxford University Press: New York, 1989, p. 72.

141. Taylor, E. W.; Nikam, S. S.; Lambert, G.; Martin, A. R.; Nelson, D. L.; Mol. Pharmacol. 1988, 34, 42.

142. Hibert, M. F.; Trumpp-Kallmeyer, S.; Bruinvels, A.; Hoflack, J.; Mol. Pharmcol. 1991, 40, 8.

143. Trumpp-Kallmeyer, S.; Hoflack, J.; Bruinvels, A.; Hibert, M.; J. Med. Chem. 1992, 35, 3448.

144. Mokrosz, J. L.; Duszynska, B.; Pol. J. Pharmacol. Pharm. 1992, 44, 527.

145. Campbell, S. F.; Davey, M. J.; Hardstone, J. D.; Lewis, B. N.; Palmer, M. J.; J. Med. Chem. 1987, 30, 49.

146. López-Rodriguez, M. L.; Morcillo, M. J.; Fernández, E.; Porras, E.; Orensanz, L.; Beneytez, M. E.; Manzanares, J.; Fuentes, J. A.; J. Med. Chem. 2001, 44, 186. 